\title{
Análise da probabilidade de bloqueio devido ao controle de potência em sistemas CDMA
}

\author{
Renato Batista Pinheiro, Rafael Saraiva Campos e Lisandro Lovisolo
}

\begin{abstract}
Resumo-Este trabalho apresenta uma abordagem para estimar a probabilidade de bloqueio de chamadas no sistema CDMA a partir da interferência total em cada setor provocada pelos usuários ativos no sistema
\end{abstract}

Palavras-Chave-CDMA, Interferência, Probabilidade de Bloqueio, Controle de Potência.

Abstract-This work presents an approach to estimate the call blocking probability in the CDMA system from the total interference in each sector, caused by active users in the system.

Keywords-CDMA, Interference, Blocking Probability, Power Control.

\section{INTRODUÇÃO}

Neste artigo é realizada uma simulação computacional no MATLAB para estimar a distribuição espacial da probabilidade de bloqueio de chamadas e o número máximo de usuários ativos por setor em um sistema CDMA (Code Division Multiple Access) [1] considerando apenas o soft blocking no enlace reverso como fator limitante. Os mecanismos de controle de potência em malha aberta (open loop) e malha fechada (closed loop) do padrão IS-95 (Interim Standard 95) foram incluídos na simulação. Mapas de predição de cobertura foram utilizados para estimar as áreas de melhor servidor de cada célula.

\section{Modelagem do Problema}

Em sistemas CDMA, o ganho de processamento $G_{p}$ exprime a melhoria da razão sinal ruído na saída do correlator relativamente a sua entrada. O cálculo do ganho de processamento é feito a partir da razão entre a taxa de chips $R_{c}$ e a taxa de bits $R_{b}$ do sinal em banda básica multiplicada pelo fator de atividade de voz $F_{a v}$ :

$$
G_{p}(d B)=10 \log \left[R_{c} /\left(R_{b} \cdot F_{a v}\right)\right]
$$

A potência de ruído térmico, na ausência de interferências adicionais em relação ao ruído térmico $\left(N_{r}\right.$ - noise rise $)$, é dada por:

$$
P_{o}(d B m)=N_{o}+F_{r}+10 \log (B)
$$

onde $N_{o}$ é a densidade espectral de ruído térmico em $\mathrm{dBm} / \mathrm{Hz}$, $F_{r}$ é o fator de ruído do receptor em dB e $B$ é a largura de banda da portadora CDMA em Hertz. A sensibilidade do receptor da ERB (Estação Rádio Base), considerando apenas o ruído térmico, é dada por:

$$
S_{o}(d B m)=P_{o}+E_{b} / N_{o}-G_{p}
$$

Renato Batista Pinheiro, Rafael Saraiva Campos e Lisandro Lovisolo, Faculdade de Engenharia, Programa de Engenharia Eletrônica, Universidade do Estado do Rio de Janeiro, Rio de Janeiro, Brasil, E-mails: renatobpinheiro@yahoo.com.br, rafael_saraiva@ig.com.br, lisandro@uerj.br. onde $E_{b} / N_{o}$ é a razão sinal-ruído mínima em $\mathrm{dB}$ do sinal banda básica para que ocorra recepção sem erro.

A área de teste foi dividida em quadrados com largura $r$ metros, referidos neste trabalho como pixels. Seja então o $i$ ésimo pixel localizado na área de melhor servidor do $j$-ésimo setor. No enlace direto, a perda total no enlace entre a antena transmissora do setor $j$ e o pixel $i$ é dada por:

$$
L_{i, j}(d B)=T X_{j}-R X_{i, j}
$$

onde $R X_{i, j}$ é a potência em $\mathrm{dBm}$ recebida no pixel $i$ do setor $j$ e $T X_{j}$ é a potência de transmissão da antena do setor $j$ em $\mathrm{dBm}$. Assumiu-se que as perdas nos enlaces direto e reverso são iguais.

A potência de transmissão mínima, i.e, na ausência de carregamento e interferências externas, necessária para uma estação móvel (EM) situada no pixel $i$ comunicar-se com o setor $j$ é dada por:

$$
P_{\min }(d B m)=L_{i, j}+S_{o}
$$

A potência interferente total aumenta com a admissão de novos usuários no sistema. Isso exige uma elevação da potência de transmissão dos móveis ativos, a fim de manter a razão sinal-ruído constante. Porém, devido ao limite máximo da potência de transmissão da EM, o sistema deve bloquear um novo usuário caso o efeito dessa nova interferência exija uma potência de transmissão superior à $P_{\max }$ de pelo menos uma EM ativa no sistema. A potência interferente total no jésimo setor, proveniente das EMs ativas neste setor, é dada por:

$$
R_{j}(\mathrm{dBm})=10 \log \sum_{i=1}^{n_{j}}\left(n_{i} \cdot p_{i} \cdot 10^{-0,1 \cdot L_{i, j}}\right)
$$

onde $p_{i}$ é a potência de transmissão $(\mathrm{mW})$ das EMs no pixel $i, n_{i}$ é o número de EMs ativas no pixel $i$ e $n_{j}$ é o número de pixels com usuários ativos no setor $j$.

O noise rise $N_{r}$ no $j$-ésimo setor é calculado considerando, além da potência interferente $R_{j}$ dos usuários na mesma célula, a interferência proveniente dos usuários ativos nos setores vizinhos. Esta interferência adicional é representada através do fator de eficiência de reuso de frequência $F_{r f}$ [2]. O noise rise no setor $j$ é dado por:

$$
N_{r}(d B)=10 \log \left[\frac{10^{0,1 \cdot R_{j}}+10^{0,1 \cdot P_{o}}}{F_{r f} \cdot 10^{0,1 \cdot P_{o}}}\right]
$$

A sensibilidade do receptor no $j$-ésimo setor, considerando a interferência inter-usuários no enlace reverso, é dada por:

$$
S(d B m)=S_{o}+N_{r}
$$

Portanto, verifica-se que a sensibilidade depende do valor de $N_{r}$, que varia com o número de usuários ativos no setor e suas potências de transmissão. De posse dessas equações, pode-se calcular a quantidade de usuários admitidos no sistema, tendo como fator limitante a interferência total no enlace reverso em cada setor. 


\section{AplicaÇÃo PRÁtica}

Para aplicar o procedimento descrito, utilizou-se uma área quadrada de $4,84 \mathrm{~km}^{2}$ no Centro do Rio de Janeiro, ilustrada na Fig. 1. Esta região foi dividida em pixels de $5 \times 5 \mathrm{~m}^{2}$. Através do software de planejamento de cobertura PLANET, foram identificados os setores melhores servidores e os respectivos níveis de sinal recebidos em cada pixel. Foram simuladas tentativas de comunicação dos usuários com as estações base de modo aleatório, utilizando o método Monte Carlo no MATLAB. A densidade superficial de usuários foi considerada uniforme sobre a área de teste. Assim, a probabilidade de existir um usuário em um dado pixel é dada por:

$$
P_{u s}=D_{u s} / D_{p}
$$

onde $D_{u s}$ é a densidade de usuários (usuários $/ \mathrm{km}^{2}$ ) e $D_{p}$ é a densidade de pixels (pixels $/ \mathrm{km}^{2}$ ).

A dinâmica da simulação consiste em varrer aleatoriamente todos os pixels do sistema, verificando se há tentativa de acesso por estações móveis localizadas nos pixels. À medida que cada usuário acessa o sistema, sua transmissão provoca um aumento na interferência total do setor. Para não exceder o limite de interferência admitido pelo sistema, verifica-se a repercussão da interferência provocada por cada tentativa de entrada (isto é, por um novo usuário) nos usuários já conectados ao sistema. A admissão de novos usuários em cada célula é bloqueada quando se verifica que a interferência provocada por um novo usuário implicaria na queda da chamada de um usuário ativo na mesma célula.

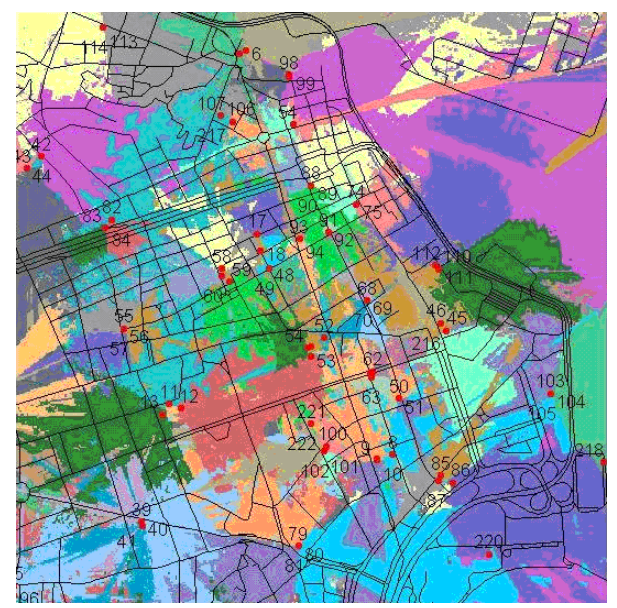

Fig. 1. Mapa com ás areas de melhor servidor preditas.

\section{Resultados}

Com base no que foi visto anteriormente, pode-se calcular a probabilidade de bloqueio $P_{b, i}$ no $i$-ésimo pixel através de:

$$
P_{b, i}=U_{b, i} / U_{s, i}
$$

onde $U_{s, i}$ é a quantidade de simulações em que há usuários no $i$-ésimo pixel tentando acessar o sistema e $U_{b, i}$ é a quantidade de usuários bloqueados dentre as tentativas realizadas neste pixel. As considerações e parâmetros de entrada adotados, típicos de um sistema CDMA IS-95 [3], são listados a seguir: i) perdas de propagação iguais nos enlaces direto e reverso, calculadas pelo modelo de Okumura-Hata [4]; ii) temperatura de operação do sistema $300 \mathrm{~K}$; iii) $R_{b}=9600 \mathrm{bits} / \mathrm{s}$; iv) $R_{c}=$ 1,2288 Mcps; v) $F_{a v}=0,5$; vi) $F_{r f}=0,68$; vii) $N_{o}=-174$ $\mathrm{dBm} / \mathrm{Hz}$; viii) $F_{r}=5 \mathrm{~dB}$; ix) $B=1,2288 \mathrm{MHz}$; x) frequência central da portadora $875 \mathrm{MHz}$.

Foram escolhidos dois cenários distintos para as simulações. No primeiro cenário, utilizou-se $E_{b} / N_{o}$ alvo de $7 \mathrm{~dB}$ e densidade de usuários de 2.500 usuários $/ \mathrm{km}^{2}$. No segundo cenário, utilizou-se $E_{b} / N_{o}$ alvo de $10 \mathrm{~dB}$ e densidade de usuários de 10.000 usuários $/ \mathrm{km}^{2}$. Foram realizadas 1.000 simulações em cada cenário. A Fig. 2 mostra os mapas da probabilidade de bloqueio por pixel para os dois cenários. Observa-se uma elevação da probabilidade de bloqueio de acesso em torno de 20 a 30 \% na área de teste, ao quadruplicar-se a densidade superficial de usuários e dobrar-se a relação sinal ruído alvo. Para as condições de carregamento simuladas, observa-se extensas áreas com elevada probabilidade de bloqueio. Em tais casos, ações globais para ampliação de capacidade, como acréscimo de portadoras CDMA, ou pontuais, como ativação de novas ERBs, podem ser adotadas para melhorar o acesso na interface aérea.

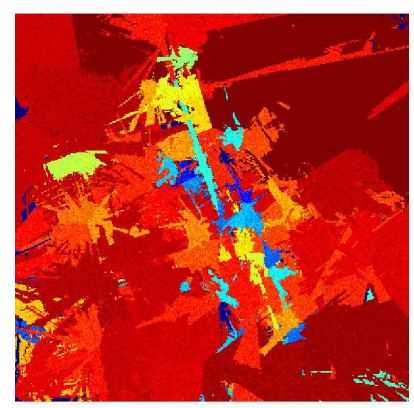

(a)

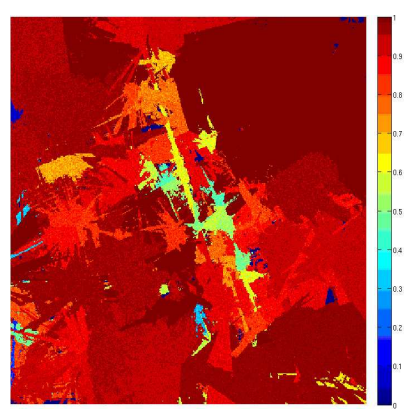

(b)
Fig. 2. Mapas de probabilidade de bloqueio de acesso.

\section{Conclus Ão}

Através do algoritmo apresentado neste trabalho pode-se estimar a probabilidade de bloqueio e a quantidade de usuários aceitos em cada setor, considerando como fator limitante a interferência inter-usuários no enlace reverso, atualizada a cada nova tentativa de admissão na interface rádio.

$\mathrm{Na}$ área estudada nota-se que a probabilidade de bloqueio de chamada em alguns setores é muito elevada. Os mapas de probabilidade de bloqueio de acesso por pixel facilitam a identificação de áreas problemáticas, auxiliando na escolha de ações de otimização da rede de acesso rádio.

Com algumas modificações, o algoritmo aqui apresentado pode ser aplicado também em redes WCDMA (Wideband CDMA).

\section{REFERÊNCIAS}

[1] Samuel C. Yang, CDMA RF System Engineering, Artech House, 1998.

[2] Lawrence Harte, CDMA IS-95 for cellular and PCS, McGraw-Hill Professional, 1999.

[3] Robert Akl, Manju Hegde e Alex Chandra, CDMA Capacity Allocation and Planning, Washington University, 1998.

[4] Simon Haykin e Michael Moher, Modern Wireless Communications, Prentice Hall, 2004. 